\title{
EFFECT OF NEURAL MOBILIZATION ON BALANCE, FLEXIBILITY, STRENGTH AND GAIT IN STROKE PATIENTS
}

${ }^{1}$ Rosimere de Lima Souza, ${ }^{1}$ Karine Rocha Moriz, 'Francisca Deyze Reis Teixiera, ${ }^{1}$ Adriano Araújo Fernandes, 'Sinval Souza da Costa Neto, 'Maria Dulce Dias De Oliveira, 'Thiago dos Santos Maciel, ${ }^{2}$ Fernando Zanela Da Silva Areas.

\begin{abstract}
Background: Neural mobilization is characterized by the neurodynamics of the nervous system with the objectives of: reducing musculoskeletal tension and pain and increasing muscular endurance and strength. Stroke is a worldwide health problem due to the impacts on quality of life, and makes the physical capacity of individuals after stroke about $40 \%$ lower of normal individuals of the same age. Objective: To verify the efficacy of neural mobilization in patients with stroke. Methods: This is a blinded randomized clinical trial performed in 12 volunteers, aged between 20 and 80 years, with a diagnosis of ischemic or hemorrhagic stroke. It was performed five mobilizations of 60 seconds in the bilateral sciatic nerve. The degree of balance and gait of the volunteers was verified, as well as the muscular strength and flexibility of the quadriceps and hamstrings muscles pre-mobilization, immediately after and after 10 sessions performed three times a week. Results: Neural mobilization on neurological patients showed positive effects in relation to flexibility, lower limb muscle strength, gait and balance. Conclusion: The present study demonstrated that the technique of neural mobilization can present good results in neurological patients with stroke sequelae. However, it is suggested that more studies be done with a larger number of volunteers and with a homogeneous sample on the approach of this technique in patients with neurological sequelae.
\end{abstract}

Keywords: Stroke; Neural Mobilization; Rehabilitation

\section{INTRODUCTION}

The Cerebrovascular Accident (CVA), also known as "stroke", is one of the leading causes of deaths in Brazil. The patients affected by this pathology may present difficulty in walking, muscle weakness, reduction in range of motion and changes in balance and motor coordination. Stroke is among the major causes of death and functional incapacity, which generates financial loss to the public funds ${ }^{(1,2)}$.

The CVA is a global health problem ${ }^{(3)}$ due to the impact on quality of life and the increase in the risk factors associated with falls, as well as the systemic complications observed in individuals with hemiparesis ${ }^{(4)}$. In Brazil, it continues to be a public health problem, overcoming coronary diseases ${ }^{(5,6)}$. According to Macko $^{(4)}$ the physical capacity of individuals after CVA is $40 \%$ lower when compared to normal individuals of the same age. These functional changes favor physical inactivity and third-party dependence, especially in relation to locomotion and functional activities such as sitting and getting up and going up and down stairs.
Among the manual therapy techniques for the treatment of CVA, there is the Neural Mobilization (NM). The NM is characterized by mechanical stretching of the nervous system, which occurs through passive or active oscillatory movements with the purpose of decreasing neural tension, reducing pain and improving muscle flexibility and endurance. Neural mobilization improves the elasticity of nervous and musculoskeletal tissues due to the increase of the intraneural blood flow and improvement of the axoplasmatic flow ${ }^{(7,8)}$.

The therapeutic effects of the NM have been described in the literature. In a randomized double-blind clinical trial conducted by Maciel el al. (2012) the neural mobilization promoted maintenance in the levels of strength, muscle recruitment and resistance in the flexor muscles of wrist and fingers ${ }^{(9)}$. According to Valente et al. (2014) the neural mobilization is also able to provide increased flexibility, this fact was observed in the Fingertip-to-floor test ${ }^{(10)}$. Therefore, this study aims to observe the possible effects of neural

Corresponding Author: MSc Prof. Fernando Zanela da Silva Arêas. FEFF - Faculdade de Educação Física e Fisioterapia. Av. Rodrigo Otávio, 3200 - Coroado, Manaus - AM, 69077-000. e-mail: fernandozanela@hotmail.com

2 Universidade Federal do Amazonas, FEFF-Manaus - AM, Brasil.

Full list of author information is available at the end of the article.

Financial support: This study was funded by the Federal University of Amazonas (UFAM)/Fundação de Amparo à Pesquisa do Estado do Amazonas (FAPEAM) through the Programa de Apoio a Iniciação Científica (PAIC). 
mobilization in patients with stroke. It was investigated the effects of neural mobilization in relation to: muscular strength, flexibility, balance, functionality and gait.

\section{METHODS}

\section{Ethical aspects}

The entire procedure was approved by the Ethics Committee on Human of the Federal University of the Amazonas CAAE 12754413.5.0000.5020. Prior to the study, the volunteers completed and signed the Informed Consent Form, regarding the objectives and procedures to which they were submitted.

\section{Study design}

It is a blinded randomized clinical trial. The intervention was performed in the laboratory of Neurological Physiotherapy of the Federal University of the Amazonas (UFAM), located in the Institute of Health and Biotechnology in the city of Coari-AM. The sample consisted of 12 (twelve) volunteers, aged between 20 and 80 years of both genders, with a diagnosis of ischemic or hemorrhagic CVA.

From the twelve volunteers, eleven fit the inclusion criteria and one was excluded from the study, in which nine were right hemiparetic and two left hemiparetic. The inclusion criteria were: patients with CVA, age between 20 and 80 years, cooperative, stable clinical state, normal cognition. The exclusion criteria were subjects who presented: cardiac disorders, rheumatic and orthopedic diseases that would impede the performance of the technique, uncontrolled blood pressure, aphasia and cognitive or communication alterations that would impede the understanding of the study, or who have undergone some type of surgery recently.

\section{Procedures}

The evaluation procedures were performed in three phases: pre-intervention (before the first session), immediately after (evaluation after the technique application) and after the tenth session (final evaluation). All the volunteers were submitted to the evaluation of the flexibility and the strength of the quadriceps and hamstrings muscles, and were also evaluated the balance and the gait of them. Each measure mentioned above had a specific evaluator. To increase reliability, pleximetry and dynamometry were performed three times, and was used the arithmetic mean of the three values.

The evaluation of the flexibility of the lower limbs was tested through the fleximeter of $\operatorname{Code}^{\circledR}{ }^{\circledR}$ Fleximeter $^{\circledR}$, São Paulo, SP, Brazil). The evaluator fixed the fleximeter with a Velcro on the ankle of the lower limb (LL) to be assessed, and then it was fixed in the contralateral LL to be tested. The hamstring flexibility was evaluated by the straight leg raising test. The volunteer was in supine position, legs extended, lumbar spine and sacrum in neutral position and the evaluator passively raised the assessed LL until the volunteer reported stretching of the musculature, keeping the knee extended and the foot in neutral position, and the device recorded the value automatically, while the contralateral leg was fixed on the stretcher. In order to check the flexibility of the quadriceps, the volunteer was positioned in ventral decubitus, and the evaluator fixed the fleximeter in the ankle of the evaluated LL, and passively performed the knee flexion until the volunteer reported total quadriceps stretching, the value was recorded in the device.

To evaluate the muscular strength was used an analog dynamometer Filizola ${ }^{\circledR}$ (CROWN 200 kgf, São Paulo-SP Brazil). The volunteer was positioned sitting in an extensor chair with the back supported, knees at 90 degrees, and the dynamometer was fixed with a Velcro in the ankle of the evaluated LL. In order to verify the strength of the quadriceps, the volunteer was positioned ergonomically on the equipment and performed extension of the knee with the verbal command of the evaluator; the value was registered automatically in the device and then the contralateral LL was tested. To verify the strength of the hamstrings, the volunteer was positioned ergonomically in the equipment and performed a knee flexion with the verbal command of the evaluator; the value was registered in the device.

The balance evaluation was based on the Berg Balance Scale (BBS), Brazilian version ${ }^{(10)}$. The BBS quantitatively assesses the ability of patients to maintain balance and postural control during the performance of daily functional activities, as well as to determine risk factors for loss of independence and for falls. The scale evaluates the functional balance, based on 14 common items of daily life, such as reaching, turning, standing and getting up. The maximum score that can be achieved is 56 points. Each of the 14 items has five possible punctuation alternatives; zero refers to a situation of incapacity or extreme need to a third-party to perform the activity, while score five demonstrates total independence.

The gait evaluation was performed through the Timed up and go test which is a reliability test recognized in the literature, developed in an attempt to quantify the mobility performance through the speed of the individual in performing the task ${ }^{(11)}$. The test requires that the volunteer raise from a standardized chair with support but without arms, when the evaluator command the patient must walk 3 meters, turn $180^{\circ}$ and return to the chair and sit down again. The test quantifies in seconds the functional mobility, through the time that the individual accomplishes the task ${ }^{(12)}$.

After the evaluation, the neural mobilization technique was applied to the bilateral sciatic nerve, using five different movements, three movements with the extended leg (proximal mobilization of the nerve) and two with the flexed leg (distal mobilization of the nerve). Neural mobilization techniques include repetitive movements of the proximal and/or distal segments, which reproduce symptoms in the mobilized 
nerves and muscles ${ }^{(13)}$. Each movement of mobilization had the duration of 60 seconds, with interval of 60 seconds from a mobilization to another. The proposed treatment protocol was performed individually, at a frequency of three times a week, during 10 sessions.

The first stage of the neural mobilization was performed with the volunteer in supine position on the stretcher, legs extended, lumbar spine and sacrum in neutral position, and head resting on a pillow (causing comfortable flexion of the cervical spine). Initially the therapist raised the leg to be mobilized, with the knee extended, and the foot in neutral position. Then performed dorsiflexion oscillations of the foot (until reaching the level of sensibility, i.e., range of motion and pain) and the knee extended ${ }^{(13)}$.

In the second stage, the mobilization was applied with the volunteer in the same position of the first stage. However, the therapist does a dorsiflexion on the volunteer and elevates the leg to be mobilized (until reaching the level of sensitization) and holds on his shoulder, sits laterally on the stretcher and then performs the oscillatory movements of hip flexion, maintaining the dorsiflexion and extension of the knee.

In the third stage, the neural mobilization was applied with the volunteer in the same position of the first and second stage. The therapist dorsiflexes and raises the leg to be mobilized (until reaching the level of sensitization) and holds on his shoulder, sits laterally on the stretcher and then performs the oscillatory hip flexion movements (when the therapist increases the amplitude of hip flexion maintains the dorsiflexion and when the one performed the reduction of the amplitude of hip flexion performed plantar flexion) with the knees extended.

In the fourth stage, neural mobilization was applied with the volunteer in supine position on the stretcher, legs extended, lumbar spine and sacrum in neutral position, and head resting on a pillow (causing comfortable flexion of the cervical spine). The therapist performed a dorsiflexion on the LL, then hip flexion with stabilization of the knee by $90^{\circ}$. The physiotherapist maintained this position and performed oscillatory dorsiflexion movements.

In the fifth stage of the technique, the mobilization was applied with the volunteer in the same position of the fourth movement. However, the therapist maintained a dorsiflexion on the LL with the knee flexed at $90^{\circ}$ and then performed oscillatory movements of the hip joint.

At the end of the 10 sessions was performed the final evaluation, in which the data were analyzed and then the results were compared.

\section{Data analysis}

The Shapiro-Wilk test was performed to analyze the normality of the data. Then, because it was a non-parametric sample in three different moments of evaluation (pre-intervention, immediately after and after ten sessions), was used the Friedman test. To verify the correlation between the variables the Spearman's rank correlation test was applied. $\mathrm{P}<0.05$ was accepted as significant values. The statistical programs used were the BioEstat 5.0 (Federal University of Pará, Belém, Pará) and the GraphPad Prism 5.0 (Graphpad, Ca, EUA).

\section{RESULTS}

The present study was performed with 11 volunteers. It was observed that the right quadriceps and left hamstrings muscles had a significant increase in flexibility immediately after the application of the neural mobilization technique (Table 1). There was also an increase in muscle strength levels in the right and left quadriceps, as well as in the left hamstrings. However, the right hamstrings strength remained unchanged (Table 2).

There was a significant difference in the time performing the Timed up and go test after the 10th neural mobilization session (Figure 1).

Table 1: Assessment of the flexibility of the quadriceps and hamstrings muscles.

\begin{tabular}{|c|c|c|c|}
\hline & Pre $M \pm D P$ & Immediately after $\mathrm{M} \pm \mathrm{DP}$ & After 10 sessions $\mathrm{M} \pm \mathrm{DP}$ \\
\hline Left Quadriceps & $112^{\circ} \pm 18$ & $122^{\circ} \pm 21^{*}$ & $122^{\circ} \pm 15^{*}$ \\
\hline Right Quadriceps & $109^{\circ} \pm 22$ & $122^{\circ} \pm 24$ & $125^{\circ} \pm 15$ \\
\hline Left Hamstrings & $84^{\circ} \pm 14$ & $96^{\circ} \pm 13^{*}$ & $92^{\circ} \pm 12^{*}$ \\
\hline Right Hamstrings & $86^{\circ} \pm 15$ & $93^{\circ} \pm 17$ & $91^{\circ} \pm 12$ \\
\hline
\end{tabular}

Note: Mean (M) and Standard deviation (DP), ${ }^{*} p<0.05$ pre-neural mobilization $\mathrm{X}$ post-neural mobilization.

Table 2: Assessment of the strength of the quadriceps and hamstrings muscles. Note: Mean (M) and Standard deviation (DP), ${ }^{*} p<0.05$ pre-neural mobilization $\mathrm{X}$ post-neural mobilization.

\begin{tabular}{|c|c|c|c|}
\hline & Pre $\mathbf{M} \pm \mathrm{DP}$ & Immediately after $\mathrm{M} \pm \mathrm{DP}$ & After 10 sessions $M \pm D P$ \\
\hline Left Quadriceps & $22 \pm 6$ & $23 \pm 6$ & $26 \pm 7$ \\
\hline Right Quadriceps & $21 \pm 9$ & $21 \pm 7$ & $24 \pm 9$ \\
\hline Left Hamstrings & $10 \pm 4$ & $11 \pm 4$ & $12 \pm 4$ \\
\hline Right Hamstrings & $8 \pm 5$ & $9 \pm 6$ & $11 \pm 7^{*}$ \\
\hline
\end{tabular}




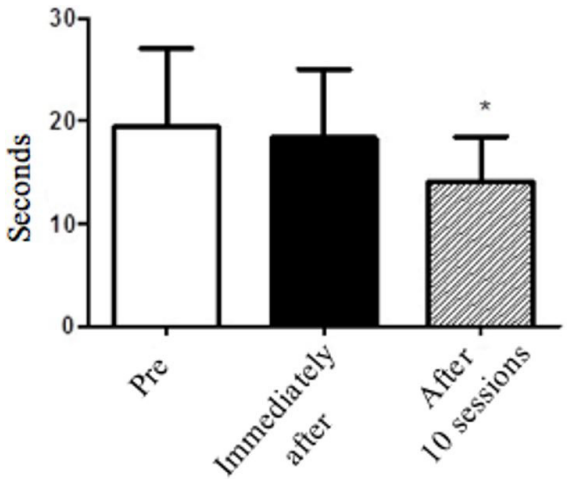

Figure 1: Timed Up and Go Test. Note: ${ }^{*} p<0.05$ Pre X After 10 sessions; Pre $=19 \pm 7$; Immediately after $=18 \pm 6$; after 10 sessions $=14 \pm 4^{*}$.

Table 3: BERG Scale.

\begin{tabular}{ccc}
\hline Pre $\mathbf{M} \pm \mathbf{D P}$ & $\begin{array}{c}\text { Immediately After } \\
\mathbf{M} \pm \mathbf{D P}\end{array}$ & $\begin{array}{c}\text { After } 10 \text { sessions } \\
\mathbf{M} \pm \mathbf{D P}\end{array}$ \\
\hline $45 \pm 11$ & $48 \pm 6^{*}$ & $52 \pm 3.5^{* *}$ \\
\hline
\end{tabular}

Note: ${ }^{*} \mathrm{p}<0.05$ Pre X Immediately After; ${ }^{* *} \mathrm{p}<0.001$ Pre X After 10 sessions.

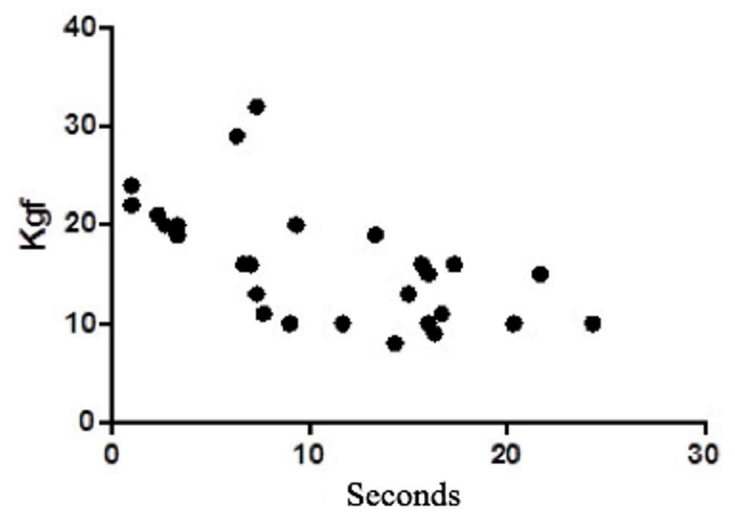

Figure 2: Correlation between the strength of the right hamstrings and the time performing the Timed up and go test. Note: $r=-0.7130$ (Strong negative correlation) $p<0.0001$

The results obtained (Table 3 ) showed that the patients in the first evaluation of this study presented static and dynamic balance deficit, but during the immediately after evaluation and after the tenth session of the neural mobilization application, there was improvement in the balance. Figure 2 shows the strong negative correlation between the right hamstrings strength and the time performing the Timed up and go test.

\section{DISCUSSION}

Stroke is one of the main causes of death and the main cause of functional incapacity in the world ${ }^{(1)}$. Therefore, this study aimed to verify the effect of neural mobilization in relation to strength, muscle flexibility, gait and balance of patients affected by stroke, after the application of neural mobilization techniques. Neural mobilization assumes that, if there is impairment of the mechanics and/or physiology of the nervous system (movement, spasticity, conduction, axoplasmic flow), dysfunctions may occur in the system itself or in musculoskeletal structures receiving innervation ${ }^{(7,8)}$.

Neural mobilization may influence muscle strength, since it correlates neuromuscular adaptation to exercise, i.e., it depends on the integrity between central and peripheral nervous systems that are interconnected ${ }^{(15)}$. According to Maciel $^{(9)}$ et al (2012) neural mobilization may present maintenance levels of muscle recruitment and strength when performed before exercise, improving physical performance. In the present study, it was observed increased levels of muscle strength in the right and left quadriceps, as well as in the left hamstrings. However, the right hamstrings strength remained unchanged.

The increased strength levels of the left quadriceps and hamstrings muscles possibly influenced the gait and speed of the Timed up and go test after the ten sessions of neural mobilization, due to the improvement of the axoplasmatic flow and local blood supply caused by the oscillatory maneuvers performed in the sciatic and femoral nerves as well as in the extensor and flexor muscles of the knee ${ }^{(15,16)}$.

In this study, it was observed an increase in the hamstring and quadriceps flexibility after neural mobilization in adult hemiplegic patients, possibly because of the improvement in tissue thixotropy and reduction of tension in nervous and muscle tissues. Similar results were observed in the study of Valente ${ }^{(10)}$ et al. (2014) after the application of the neural mobilization technique in the Fingertips-to-ground test, which increased flexibility of the posterior chain.

In hemiplegic patients who have suffered brain damage, the response to automatic control of posture is interrupted, contributing to impaired balance, leading to gait difficulty and risk of falls ${ }^{(15)}$. According to Shacklock ${ }^{(16)}$, the effectiveness of this approach for flexibility and pain in patients with some type of musculoskeletal injury is well described in the literature, however, it is believed that neural functions are more effective by improving the axoplasmatic flow ${ }^{(17,18)}$.

In the present study, it was observed that the Timed up and go test and the static and dynamic balance also improved after performing the neural mobilization technique in the sciatic and femoral nerves, demonstrating that the muscular strength of the lower limbs is possibly related to the balance and gait quality. According to Kerrigan ${ }^{(18)}$, hemiplegic patients with inadequate knee flexion in the swing phase may impair change in muscle activity. According to Kim and Eng ${ }^{(19)}$, the variability in gait velocity and climbing stairsperformance can be attributed from $66 \%$ to $72 \%$ to the muscular strength of the lower limbs, and the authors suggest that measures of muscular strength be incorporated in the evaluation of the locomotion of subjects after a stroke, since deficits of strength imply in decreasing the speed of it. 
Matsudo ${ }^{(20)}$ et. al (2003) revealed that an increase in the muscular strength of the lower limbs makes the march faster, showing that the strengthening of these limbs is of great importance so that these individuals can wander faster. In this study, it was identified that the neural mobilization promoted an increase in the muscular strength of quadriceps and hamstrings. This finding is justifiable, since neural mobilization facilitates the movement of axoplasmic flow, improving the health of the muscular tissue innervated by the mobilized structure, potentiating the muscular activity ${ }^{(9)}$.

\section{CONCLUSION}

According to the present study it was possible to verify that neural mobilization can present good results in neurological patients with CVA sequela in relation to the improvement of the flexibility, increase of hamstrings and quadriceps muscle strength, improvement of balance and gait quality. We suggest to perform similar studies with larger samples and more homogenies.

\section{AUTHOR'S CONTRIBUTION}

RLS: Data collection, analysis and interpretation and writing; KRM: Data collection; FDRT: Data collection; AAF: Data collection; SCN: Data collection; MDDO: Data collection; TSM: Writing, critical review of content and approval of the final version of the manuscript; FZSA: Design and planning of the project, data analysis and interpretation and writing.

\section{CONFLICTS OF INTEREST}

The authors declare no conflicts of interest and approve the final manuscript.

\section{AUTHORS DETAILS}

1 Universidade Federal do Amazonas, ISB-Coari - AM, Brasil.

\section{REFERENCES}

1. BRASIL. Secretaria de direitos humanos; secretaria nacional de promoção defesa dos direitos humanos. Presidência da República. Dados sobre o envelhecimento no Brasil. Brasília, 2016a. Disponível em: http://www.sdh.gov.br/assuntos/pessoa-idosa/dados-estatisticos/ DadossobreoenvelhecimentonoBrasil.pdf Acessado em: 21/04/2016.

2. Carmo JB, Oliveira ERA, Morelato RL. Incapacidade funcional e fatores associados em idosos após o Acidente Vascular Cerebral em Vitória-ES, Brasil. Rev. Bras. Geriatr. Gerontol. 2016; 19(5):809-818

3. Williams GR. Incidence and characteristics of total stroke in the United States. BMC Neurology.2001;1:2
4. Macko RF, Smith GV, Dobrovolny CL, Sorkin JD, Goldberg AP, Silver KH. Treadmill training improves fitness reserve in chronic stroke patients. Archives of Physical Medicine and Rehabilitation. 2001;82:879-884.

5. Ministério da saúde,http://portal.saude.gov.br/portal/aplicacoes/ noticias/default.cfm?pg=dspDetalheNotici\&id_area $=1450 \& C_{\text {_ }}$ NOTICIA=10817, 2010

6. Corriveau H, Hébert R, Raîche M, Prince F. Evaluation of postural stability in the elderly with stroke. Archives of Physical Medicine and Rehabilitation. 2004;85:1095-1101.

7. Butler DS. Mobilização do Sistema Nervoso. São Paulo: Manole; 2003.

8. ShackLock M. Neurodinâmica Clínica, $1^{\circ}$ edição, Rio de Janeiro: Elsevier, 2007.

9. Maciel TS, Da Cruz VWC, Jorge FS, Areas FZS, Ribeiro Junior SM. Efeitos da mobilização neural na força, resistência e recrutamento muscular dos flexores de punho. MTP\&RehabJournal. 2012;10(50):411-416.

10. Valente PS, Valente PS, Augusta S, Arêas GPT, Freire Jr RC, Maciel TS. Mobilização do plexo braquial e flexibilidade do membro inferior. MTP\&RehabJournal 2014;12:439-454

11. Loth EA, Bertoloni GRF, Albuquerque CE. Avaliação do TimedUpandGocomo preditor de quedas em uma amostra de idosas que relatam quedas. Reabilitar, 2003.

12. Gorst T, Rogers A, Morrison SC, Cramp M, Paton J, Freeman J, Marsden J. Disabil Rehabil. 2018; 4:1-8.

13. Shacklock M, Donoso CG, López MOL. Tratamiento Manual de dolor y lombar ciática com neurodinámica. Clínica. Fisioterapia 2007; 29:312-20

14. Ramos GV, Santos RR, Gonçalves A. Influência do alongamento sobre a força muscular: uma revisão breve sobre como possíveis causas. Rev. Bras Cineantropom Desempenho Hum. 2007; 9:203-6

15. Pohl M, Mehrolz J. Immediate effects of an individually designed functional ankle-foot orthosis on stance and gait in hemiparetic patients. Clinical Rehabilitation. 2006; 20(4): 324-330.

16. Shackock MO. Clinical Apllication of Neurodynamics. In: Moving in on Pain.

17. Brown CL, Gilbert KK, Brismee J-M, Sizer PS, Roger James C, Smith MP. The effects of neurodynamic mobilization on fluid dispersion within the tibial nerve at the ankle: an unembalmed cadaveric study. The Journal of Manual \& Manipulative Therapy. 2011;19(1):26-3

18. Kerrigan DC, Gronley J, Perry J. Sttiff-legged Gait in Spascic Paresis: A study of quadriceps and hamstrings muscle activily. Am J Plys Med Rehabil, $1991 ; 70: 294-300$

19. KIM, M ENG, J The Relationship of Lower-Extremity Muscle Torque to Locomotor Performance in People With Stroke. PhysicalTherapy. 2003; 83:49-57.

20. Matsudo SM, Matsudo VKR, Barros Neto, TL Araujo, TL. Evolução do perfil neuromotor e capacidade funcional de mulheres fisicamente ativas de acordo com a idade cronológica. Revista Brasileira de Medicina do Esporte. 2003; 9;(6):365-376. 